\title{
The challenges of international comparisons of COVID-19
}

\author{
Patricia Fitzpatrick ${ }^{1}$ (D)
}

Received: 7 September 2020 / Accepted: 12 September 2020 / Published online: 21 September 2020

(C) Royal Academy of Medicine in Ireland 2020

In the context of the COVID-19 pandemic, there has been a natural rush to international comparisons to gauge how countries have managed it. There are, however, specific challenges in interpretation of comparative COVID-19 statistics that may not always be immediately apparent, depending on a publication's stated caveats. As cases rise in many countries and second waves are anticipated, it is opportune to review comparative measures and consider if we are comparing like with like.

Age-standardised incidence and mortality rates are normally used in non-pandemic times, as differences in population structures affect these, and crude rates can be misleading [1, 2]. During this pandemic, age-standardised rates have rarely been referenced in media or political commentary. This issue is particularly relevant when mortality rates in African countries are compared with more developed countries, as the population age structure in most African countries differs, with higher birth rates and lower life expectancy [3, 4].

Number of cases per million population is a rate that is frequently reported. This is normally a useful comparison in non-pandemic times, but during the pandemic, it is challenged by two data considerations: what is the COVID-19 testing practice of different countries to identify cases, and are the countries at a similar stage of the pandemic? Aside from this, testing rates can be subject to double counting, as happened early in the pandemic in the UK [5], and remains possible [6].

Deaths per million population is a rate that many would consider a useful comparator. However, this is a crude rate whose value in the pandemic also depends on what is and is not counted as a COVID death. Although WHO published an interim definition for cause of death from COVID, countries vary; some COVID deaths reported include just those tested positive; others include those where COVID is deemed highly likely, without confirmation. Deaths occur in many settings and all should be counted in a similar way for comparison. For

Patricia Fitzpatrick

patricia.fitzpatrick@ucd.ie

1 School of Public Health, Physiotherapy \& Sports Science, University College Dublin, Belfield Dublin 4 Ireland example, in England, hospital deaths only were included in official death figures until 29 April-the UK fatality figure rose by 4419 deaths after non-hospital deaths positive for SARS-COV-2 were included (included 3811 deaths in care homes and the community going back to early March) [7]. In Belgium, $46 \%$ deaths were hospital (all confirmed) and 54\% were from care homes (with $84 \%$ of these unconfirmed) [8]. In the USA, it is thought that in the early weeks of the pandemic, reported deaths were likely underestimated because of incomplete follow-up on all reported COVID-19 cases as well as death among persons infected who did not receive a COVID-19 diagnosis [9].

Infection fatality ratio and case fatality ratio are other relevant measures, but as a comparator for COVID-19, both are challenged by testing practices, with greater testing lowering both; both are influenced also by definition of death used in comparator countries [10].

If there are adequate ICU beds in the comparative countries, the number of admissions to ICU per million population is a good comparator of disease severity. However, rates are dependent on the number of ICU beds and ventilators per 100,000 population in a country, ICU admission policies (e.g. age-related policy) in the pandemic and the stage of outbreak. If ICU bed numbers are inadequate for a population, then those patients requiring ICU for treatment of COVID cannot all be admitted, making this rate less useful for international comparisons [11].

Population density can also affect rates of COVID, although the findings are inconsistent. In the case of a highly infectious virus, it may be preferable therefore to compare in a more focussed way. The population density overall in Hong Kong is $7096 / \mathrm{km}^{2}$, in the UK is $275 / \mathrm{km} 2$ and in Ireland is $71 /$ $\mathrm{km}^{2}$. Hence, it may be more comparable to look at similarly population dense areas, such as comparable cities [12].

Data accuracy affects all comparative measures. Accurate data collection is a challenge in developing countries and will likely continue to be so in this pandemic [13].

Ethnicity may be important in international comparisons. Early deaths among ethnic minority doctors in the UK sparked interest in the possibility of ethnic differences in the 
expression of angiotensin converting enzyme 2 and risk of both acute kidney injury and cardiac complications because of a higher prevalence of cardiovascular risk factors in ethnic minority populations [14]. Fogarty et al. found a higher rate of coagulopathy in Caucasian patients in a series compared to Asian and African-American patients and concluded that pulmonary vasculopathy may contribute to the unexplained differences that are beginning to emerge highlighting racial susceptibility to COVID-19 mortality [15].

Finally, excess mortality (including COVID-19 and nonCOVID-19 deaths) may be the clearest comparison, but we will need to wait some time before accurate calculations will be possible, as this pandemic crosses the globe and further waves occur.

\section{References}

1. The BMJ. Chapter 3. Comparing disease rates. Available from: https://www.bmj.com/about-bmj/resources-readers/publications/ epidemiology-uninitiated/3-comparing-disease-rates

2. Sudharsanan N, Didzun O, Bärnighausen T, Geldsetzer P (2020) The contribution of the age distribution of cases to COVID-19 case fatality across countries. a 9-country demographic study. Ann Intern Med M20-2973. Online ahead of print

3. World Health Organisation Life expectancy. World Health Organisation, Geneva [cited 09/08/2020] Available from: https:// www.who.int/gho/mortality_burden_disease/life_tables/situation trends text/en

4. Cleland JG, Ndugwa RP, Zulu EM (2011) Family planning in subSaharan Africa: progress or stagnation? Bull World Health Organ 89:137-143

5. Boycott-Owen M, Nuki P. Tens of thousands of coronavirus tests have been double-counted, officials admit. The Telegraph. [Cited 21 May 2020] Available from: https://www.telegraph.co.uk/globalhealth/science-and-disease/tens-thousands-coronavirus-tests-havedouble-counted-officials/
6. Department of Health \& Social Care. COVID-19 testing: methodology note. London: Gov.UK. [Updated 29 July 2020; cited 09 August 2020]. Available from: https://www.gov.uk/government/ publications/coronavirus-covid-19-testing-data-methodology/ covid-19-testing-data-methodology-note

7. Office of National Statistics. Comparison of weekly death occurrences in England and Wales: up to week ending 24 April 2020. London: Office of National Statistics; updated 5 May 2020; cited 8 August 2020]. Available from: https://www.ons.gov.uk/ peoplepopulationandcommunity/healthandsocialcare/ c a u s e s of d e a th/a r t i c les/ comparisonofweeklydeathoccurrencesinenglandandwales/ uptoweekending24april2020

8. BBC Coronavirus: Why so many people are dying in Belgium. British Broadcasting Corporation, London [Updated 09 May 2020] Available from: https://www.bbc.com/news/worldeurope-52491210

9. CDC (2020) Geographic differences in COVID-19 cases, deaths and incidence - United States, February 12-April 7, 2020. Morb Mortal Wkly Rep 69:465-71

10. World Health Organisation. Estimating mortality from COVID-19. Scientific Brief. World Health Organisation, Geneva [4 August 2020; cited 8 August 2020] Available from: https://www.who.int/ news-room/commentaries/detail/estimating-mortality-from-covid19

11. Phua J, Weng L, Ling L et al (2020) Intensive care management of coronavirus disease 2019 (COVID-19): challenges and recommendations. Lancet Respir Med 8(5):506-517

12. The World Bank Population density (people per Sq. Km of land area). The World Bank, Washington D. C. [cited 09 August 2020] Available from: https://data.worldbank.org/indicator/EN.POP. DNST

13. Shaffer JG, Doumbia SO, Ndiaye D et al (2018) Development of a data collection and management system in West Africa: challenges and sustainability. Infect Dis Poverty 7(1):125

14. Khunti K, Singh AK, Pareek M, Hanif W (2020) Is ethnicity linked to incidence or outcomes of covid-19? BMJ 369:m1548

15. Fogarty H, Townsend L, Ni Cheallaigh C et al (2020) COVID19 coagulopathy in Caucasian patients. Br J Haem 189:1044-1049b

Publisher's note Springer Nature remains neutral with regard to jurisdictional claims in published maps and institutional affiliations. 